\title{
Isolation and identification of dermatophytes from collegiate runners
}

\section{L ga A Kalnina!, 3. Stephanie M Guzelak², DPM and Maryann AB Herman, PhD'.}

ISt. John Fisher College, 3690 East Avenue, Department of Biology, Rochester, NY 14618

2Dur Lady of Lourdes Memorial Hospital, I69 Riverside Drive, Binghamton, NY I3905

${ }^{3}$ Cornell University, 630 West North Street, Department of Plant Pathology and Plant-Microbe Interactions, Geneva, NY 14456

Corresponding Author: Dr. Maryann AB Herman, Associate Professor of Biology at St. John Fisher College, Rochester, NY 14618.mherman@sjfc.edu

Manuscript received 30 January, 2021; accepted 24 August 2021

Keywords: dermatophytes, collegiate runners, mycology, Fusarium spe- cies complex, fungal molecular identification 


\section{Abstract}

Competitive runners experience various risk factors that render them more susceptible to superficial cutaneous fungal infections, including the use of occlusive footwear, shared locker rooms, submission of feet to constant maceration, trauma, sweating, and having depressed immune function. The goal of this work was to assess the prevalence of athlete's foot fungi in cross country runners at St. John Fisher College. Toe webs of 16 collegiate runners were sampled and volunteers surveyed about their shoe habits, foot hygiene, and average miles run per week. Lack of tinea pedis-causing fungi in asymptomatic cross- country runners shifted the study to investigate the identities of fungi morphologically similar to athlete's foot and look for correlations with volunteers' running habits and hygiene. Thirty-five distinct fungal cultures were isolated and compared to a known Trichophyton rubrum strain both microscopically and macroscopically. Four samples were preliminarily identified as tinea pedis-causing fungi and sequenced to confirm molecular identification. Fungal DNA was isolated, purified, and PCR amplified using primers for the internal transcribed spacer region, D1/D2 region of the $28 \mathrm{~S}$ subunit, and $\beta$-Tubulin gene. Three of the four isolates were identified as Fusarium equiseti, a soil-borne plant pathogen with rare human pathogenicity reported. The fourth isolate was Beauveria bassiana, a common soil-borne pathogen that can infect immunocompromised individuals. Correct dermatophytic identification and understanding of the interplay between species is important to provide correct treatment, prevent spread among athletes and within facilities, and determine how opportunistic pathogens might play a role in people with immune suppressed function, which includes runners. 


\section{Introduction}

Athletes, particularly long-distance runners, are at high risk for tinea pedis infection as they train in occlusive footwear, use shared locker rooms, frequently endure minor foot trauma, and have periods of decreased immune function $(7,18,20,22,23,29)$. Tinea pedis, or athlete's foot, is a common superficial fungal infection caused by several dermatophytes, most commonly Trichophyton, Microsporum, and Epidermophyton species. With the increase in superficial fungal infections over the past 30 years, correct identification of tinea pedis-causing fungi is critical for epidemiological purposes, recognizing potential infection sources, and providing proper treatment, such as topical and/ or oral antifungals $(1,5,9,29)$. Many symptoms can mimic the symptoms of tinea pedis, which further indicates the need for proper identification, as incorrect treatment can lead to secondary fungal and bacterial infections $(9,11)$. Infection by non- dermatophytic molds can also result in tinea pedis. Little is known about the impact of multiple fungal species on morbidity (3). Sports-related infections can be a major cause of disease in individuals, as well as the whole team, due to close contact and sharing of equipment and facilities (20). Dermatophyte infections are difficult to cure completely and frequently recur at the initial site of infection $(7,29)$.

Clinical identification in practice is typically based on symptoms rather than morphological or molecular identification. Further morphological identification involves assessing growth rate, colony pigmentation, hyphal structure, size and shape of conidia, and examining stained foot scrapings for hyphae or pseudo hyphae $(1,3,10)$.

These methods are imprecise and can lead to incorrect identification of other fungi inhabiting the foot, as the foot hosts a plethora of other organisms. Gram positive bacteria, such as Corynebacterium minutissimum, and Candida species can cause scaling and maceration that mimic tinea pedis symptoms (10), while other soil-borne species such as Microsporum gypseum, can live on skin and cause acute infections (30). Accurate identification of asymptomatic tinea pedis and other potential opportunistic pathogens needs to be coupled to fungal morphology with a DNA sequence-based approach.

Molecular targets such as ribosomal DNA (rDNA), beta tubulin, and mitochondrial DNA (mDNA) have been successful in identifying dermatophytes to a species level (1). Many fungi can be identified by comparing the internal transcribed spacer (ITS) region of ribosomal DNA; though closely related sister taxa, significant sequence variation, and imprecise typification of species dictate the use of additional conserved sequence regions (26). The ITS region is the most commonly used target for fungal sequencing due to sensitive detection by PCR. Multiple copies of the ribosomal gene are present in all organisms and provide an optimal target for developing specific PCR primers that discriminate among closely related species (31). Additional targets, such as the $\mathrm{D} 1 / \mathrm{D} 2$ region of the $28 \mathrm{~S}$ subunit and the $\beta$-tubulin gene, provide a more robust molecular picture for dermatophyte identification (11).

The goal of this research was to investigate the prevalence of tinea pedis-causing fungi on asymptomatic cross-country runners at St. John Fisher College and look for correlations with their running habits and hygiene. It was predicted that approximately a quarter of the runners would be carriers of athlete's foot-causing fungi based on a previous survey of asymptomatic marathon runners (14). Morphological and molecular techniques were used to identify potential tinea pedis isolates to determine prevalence of specific dermatophytes among runners. Results of this work provide basic information on soil-borne fungi that are morphologically similar to tinea pedis but not typically associated with human disease complexes. Further understanding of the prevalence and interactions of these fungi with dermatophytic pathogens can help develop recommendations to reduce spread among teammates and within facilities and improve proper diagnosis and treatment. 
Table 1: Participant survey of running habits and hygiene.

\begin{tabular}{|c|c|c|}
\hline \multirow{2}{*}{ Gender } & Female & $19 \%$ \\
\hline & Male & $81 \%$ \\
\hline On average how many miles a week do you run? & \multicolumn{2}{|c|}{46.3 miles } \\
\hline \multirow{2}{*}{ Do you wear shoes inside of locker rooms at all times? } & Yes & $75 \%$ \\
\hline & No & $25 \%$ \\
\hline \multirow{2}{*}{$\begin{array}{l}\text { Do you wear shoes inside of shared showering facilities at } \\
\text { all times (ex. dorm room showers)? }\end{array}$} & Yes & $19 \%$ \\
\hline & No & $81 \%$ \\
\hline \multirow{2}{*}{$\begin{array}{l}\text { Do you wear your training shoes outside of practice and } \\
\text { competition? }\end{array}$} & Yes & $56 \%$ \\
\hline & No & $44 \%$ \\
\hline \multirow{2}{*}{ How oflen do you wash your running shoes? } & Rarcly & $56 \%$ \\
\hline & Never & $44 \%$ \\
\hline \multirow{3}{*}{$\begin{array}{l}\text { If you wash your running shoes, do you wash it in hot, } \\
\text { warm or cold water? }\end{array}$} & Hot & $11 \%$ \\
\hline & Warm & $56 \%$ \\
\hline & Cold & $33 \%$ \\
\hline \multirow{2}{*}{ Do you cver wear your running shocs without socks? } & Yes & $12.5 \%$ \\
\hline & No & $87.5 \%$ \\
\hline \multirow{2}{*}{$\begin{array}{l}\text { Do you usually scrub with soap and water your feet in the } \\
\text { shower? }\end{array}$} & Yes & $87.5 \%$ \\
\hline & No & $12.5 \%$ \\
\hline
\end{tabular}

\section{Materials and Methods}

In the fall of 2014, male and female cross- country runners at St. John Fisher College were invited to participate in this study. A document describing the purpose, methods, and risks were explained, presented to, and signed by each participant. The voluntary nature of participation and procedures for ensuring confidentiality of participants and their samples were ensured. The study was approved by St. John Fisher College Institutional Review Board (IRB) on October 2nd, 2014 (IRB File no: 3370 - 091814 - 07). Each participant completed an eight-question foot condition survey addressing their individual amounts of running, footwear habits, and foot hygiene.

\section{Sample Collection, Culture Identification, and Maintenance}

The stratum corneum of the third and fourth web spaces of both feet of 16 volunteers was sampled using a sterile swab (6). Samples were isolated on BBL Sabouraud dextrose agar (SBA) amended with $0.2 \mathrm{mg} / \mathrm{ml}$ chloramphenicol and incubated at $27^{\circ} \mathrm{C}$ for 6 days, checked daily for visible growth, then subcultured until pure (22). For spore visualization, samples were grown on Potato Dextrose Agar (PDA) at room temperature for 7 days until a visible ring pattern emerged.

\section{DNA Extraction, Sequencing and Analysis}

Samples for DNA extraction were isolated from pure fungal colonies and grown in Sabouraud dextrose broth for 7 days at room temperature using a Cel-GroTissue Culture Rotator (ThermoFisher Scientific, Waltham, MA). Fungal DNA was isolated using the PowerSoil DNA Isolation Kit (MO BIO Laboratories, Inc., Carlsbad, CA). The internal transcribed spacer region (ITS), ribosomal large subunit $\mathrm{D} 1 / \mathrm{D} 2$, and $\beta$-tubulin genes were amplified via polymerase chain reaction (PCR) using the following primers: ITS1/ ITS4 (31), ITS5/ITS4 (31), NL-1/NL-4 (13,25), Bt2a/ T1 $(9,17)$ using a BioRad T100 Thermal-Cycler. Reactions for PCR amplifications $(50 \mu \mathrm{l})$ consisted of: 35 to $50 \mathrm{ng}$ of template DNA, primers (0.2 $\mu \mathrm{M}$ each), 1x AmpliTaq 


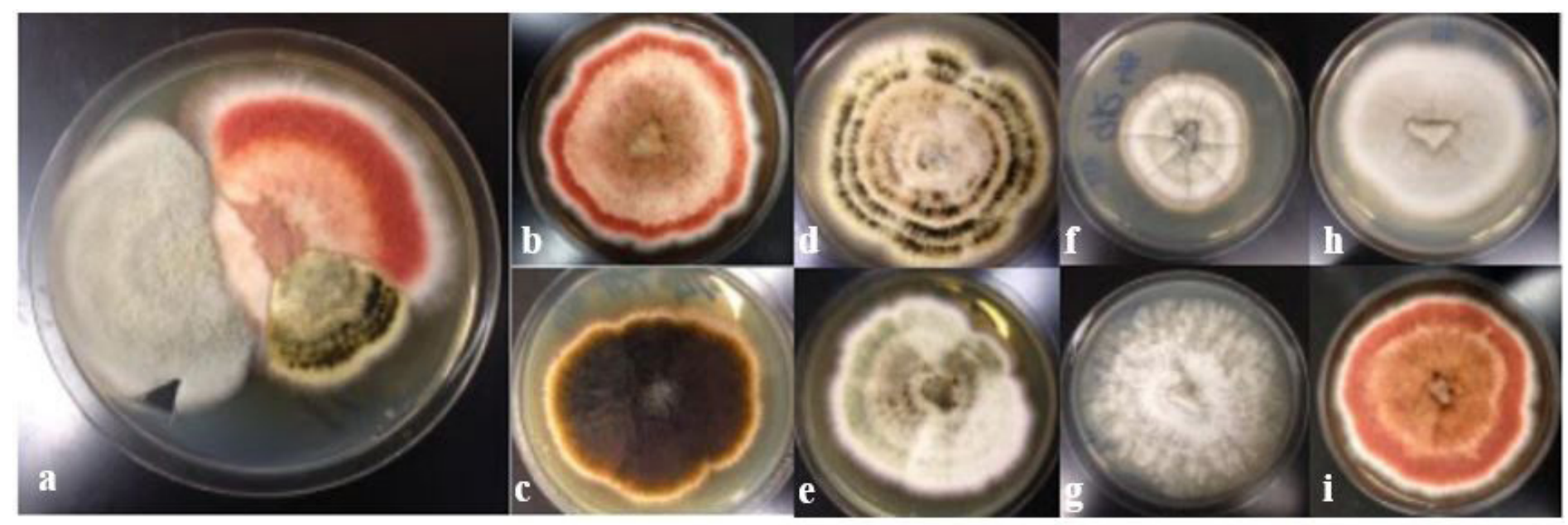

Figure 1: Macroscopic diversity of dermatophyte fungi isolated from collegiate runners. Picture (a) shows an original sample, pictures $(\mathrm{b}-\mathrm{i})$ are a representation of morphological diversity of isolated subcultures.

\section{Gold Master Mix containing 1.25 U AmpliTaq Gold DNA} Polymerase, $0.2 \mathrm{mM}$ dNTPs, $2.5 \mathrm{mM} \mathrm{MgCl} 2$, and GeneAmp PCR Gold Buffer (Applied Biosystems, Waltham, MA). Cycle parameters for ITS primer combinations were an initial denaturation at $94^{\circ} \mathrm{C}$ for $5 \mathrm{~min}$, followed by 35 cycles consisting of denaturation for $1 \mathrm{~min}$, annealing at $56^{\circ} \mathrm{C}$ for $1 \mathrm{~min}$, extension at $72^{\circ} \mathrm{C}$ for $1 \mathrm{~min}$, and a final extension at $72^{\circ} \mathrm{C}$ for $10 \mathrm{~min}(17,18)$. Cycle parameters for NL-1/NL-4 $\mathrm{Bt} 2 \mathrm{a} / \mathrm{T} 1$ primer sets were an initial denaturation at $95^{\circ} \mathrm{C}$ for $5 \mathrm{~min}$, followed by 35 cycles consisting of denaturation for $45 \mathrm{sec}$, annealing at $52^{\circ} \mathrm{C}$ for $90 \mathrm{sec}$, extension at $72^{\circ} \mathrm{C}$ for $90 \mathrm{sec}$, and a final extension at $72^{\circ} \mathrm{C}$ for $10 \mathrm{~min}(17,18)$. PCR products were visualized on a $0.8 \%$ agarose gel, purified using the E.Z.N.A. cycle pure kit (Omega bio-tek, Norcross, GA), and submitted for Sanger DNA sequencing (ACGT, Inc. Wheeling, IL). Sequences were compared with sequence entries in GenBank database using the Basic Local Alignment Search Tool for nucleotides (BLASTN) (20). Using the calculated percent identity score, specimens were assigned to a genus and species with a minimum average of $>93 \%$ homology across the primer sets used.

\section{Results}

Sixteen collegiate cross-country runners, 3 female and 13 male, participated in this study. (Table 1). Runners sampled in this study ran between 35-60 miles per week and none had active tinea pedis infections. Survey results did not yield any consistent patterns in frequency and temperature of washing 68 | Fine Focus running shoes, whether running shoes were worn in the locker room or used for outside of training, or if shower shoes were worn in the locker room. All but two volunteers always wore socks with their athletic footwear. Foot washing habits varied among participants; most runners washed their feet daily with soap and water while a few did this periodically or not at all.

Sampling both feet of each volunteer resulted in 35 distinct fungal cultures (from a total of 24 of the samples) that varied in size, shape, and color (Fig. 1). Four isolates (3R, 4R, 11R, $13 \mathrm{~L}$ ) were tentatively identified as tinea pedis-causing fungi based on their macroscopic and microscopic morphology when grown on SBA. Isolates $3 \mathrm{R}, 4 \mathrm{R}$, and $13 \mathrm{~L}$ were initially classified as Trichophyton rubrum as they exhibited chains of round macroconidia of varying shape and size and fluffy to cottony white colonies. Isolate $11 \mathrm{R}$ appeared similar to Trichophyton mentagrophytes as it grew numerous small and circular spores and exhibited small, star- shaped, white colonies (Table 2).

The four isolates morphologically similar to tinea pediscausing fungi came from male runners who ran between 40-50 miles per week, none wore their shoes without socks, and all used soap and water to scrub their feet. From the 3 runners where F. equiseti was isolated - none wore shower shoes; all wore their training shoes for other activities. Shoe washing habits varied as one runner didn't wash their running shoes, one washed with cold water, and the third washed with 


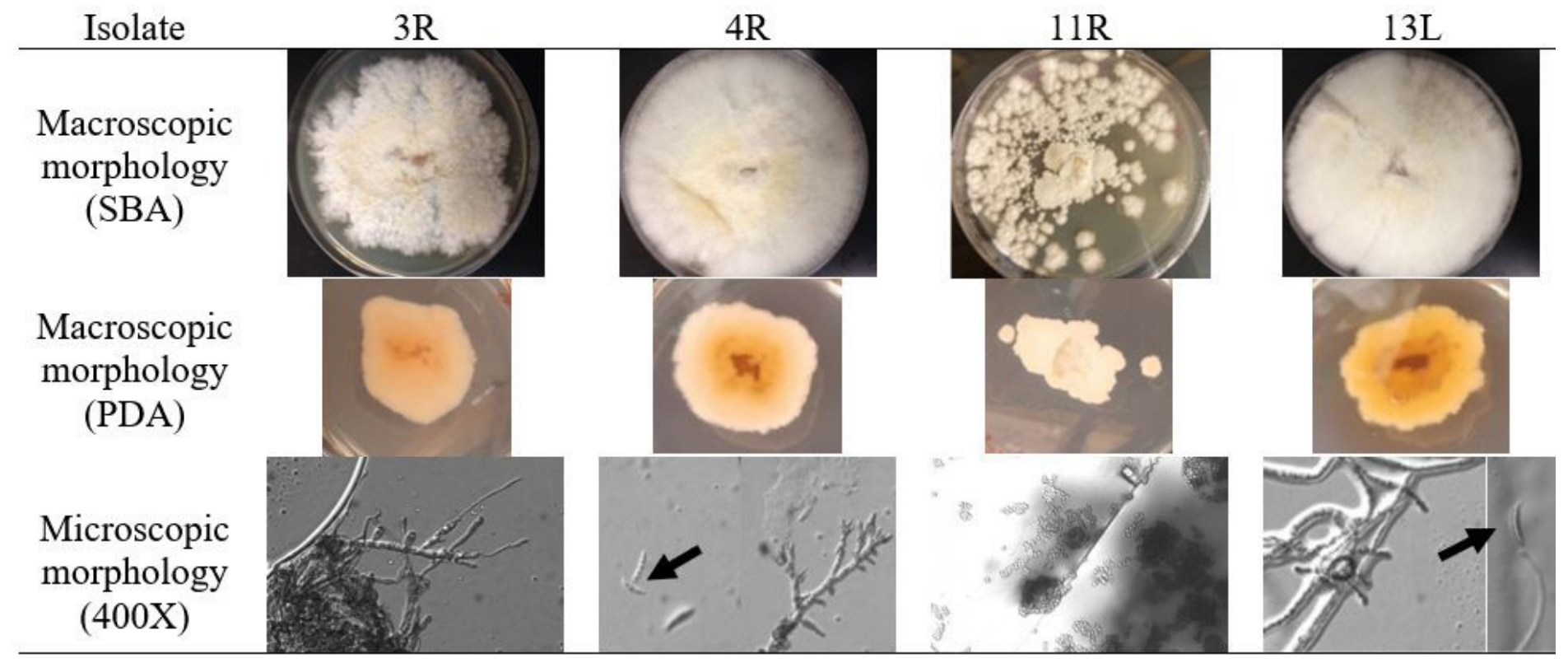

Table 2: Macroscopic and microscopic morphology of tentative tinea pedis-causing fungal isolates. Arrows highlight macroconidia.

warm water. Only one of the three wore shoes in the locker room. The runner with $B$. bassiana wore shoes in the locker room, didn't wear their running shoes outside of training, and infrequently washed their shoes in hot water.

When isolates were grown on PDA, colonies of 3R, 4R, and 13L exhibited a pink/ orange pigmentation on the underside of the colony while $11 \mathrm{R}$ still appeared white, with one large colony. Isolates 3R, 4R, and $13 \mathrm{~L}$ also produced sickleshaped, septate macroconidia with aerial conidiogenous cells. Macroconidia, typical of Fusarium species, are highlighted with arrows in microscopic morphology of isolates $4 \mathrm{R}$ and 13L in Table 2. Colony 11R grew globus, hyaline conidia on aerial hyphae.

PCR products for all samples using primer sets ITS-1/ITS4, NL-1/NL-4, and T1/Bt2b were in the 500-700 bp range, as expected. The ITS-5/ITS-4 primer set did not amplify products under the conditions tested. Top sequencing results showed $92.89-99.83 \%$ identity to the unknown isolates (Table 3). Isolates 4R and 13L were identified as Fusarium equiseti and $11 \mathrm{R}$ as Beauveria bassiana as the sequencing produced the same species for each of the six primers tested. Isolate 3R is likely Fusarium equiseti as it was the top result for four of the primers, while the D1/ D2 region of isolate 3R came back as the closely related species Fusarium incarnatum

\section{Discussion}

A range of fungi were isolated from the feet of collegiate crosscountry runners, four of which initially resembled tinea pedis species on SBA and chosen for further identification. This preliminary morphological identification is the most common method of identification of tinea pedis in clinical settings as it is accurate (particularly when an individual is symptomatic) and inexpensive $(1,3)$. DNA sequencing can be costly but has the advantages of increased sensitivity and reproducibility, minimal sample handling, and speed, compared to culturebased diagnosis $(1,26)$. Asymptomatic individuals, variation in fungal morphology, and inconsistent morphological results have created a need for more straightforward and reliable identification methods.

Runner hygiene was variable across the across the sixteen volunteers. Inconsistent habits of shoe, sock, and foot hygiene can influence the spread and survival of fungi, yet there is no standard protocol for hygiene in collegiate runners (8). Consideration of community spread of dermatophytes has led to recommendations of not wearing running shoes in the locker room, implementation of additional sanitation measures for shoes and socks, and increasing washing temperature for clothing and shoes to $60^{\circ} \mathrm{C}$ in order to kill fungal spores (8). 


\begin{tabular}{|c|c|c|c|c|c|c|c|c|c|c|c|c|}
\hline Isolate & ITS-1 & $\%$ & ITS-4 & $\%$ & NL-1 & $\%$ & NL-4 & $\%$ & $\mathrm{~T} 1$ & $\%$ & $\mathrm{Bt} 2 \mathrm{~b}$ & $\%$ \\
\hline $3 R$ & $\begin{array}{l}\text { Fusarium } \\
\text { equiseti }\end{array}$ & 97.6 & $\begin{array}{l}\text { Fusarium } \\
\text { equiseti }\end{array}$ & 98.8 & $\begin{array}{l}\text { Fusarium } \\
\text { incarnatum }\end{array}$ & 99.1 & $\begin{array}{l}\text { Fusarium } \\
\text { incarnatum }\end{array}$ & 99.6 & $\begin{array}{c}\text { Fusarium } \\
\text { equiseti }\end{array}$ & 98.5 & $\begin{array}{c}\text { Fusarium } \\
\text { equiseti }\end{array}$ & 98.3 \\
\hline $4 R$ & $\begin{array}{c}\text { Fusarium } \\
\text { equiseti }\end{array}$ & 93.5 & $\begin{array}{c}\text { Fusarium } \\
\text { equiseti }\end{array}$ & 97.7 & $\begin{array}{c}\text { Fusarium } \\
\text { equiseti }\end{array}$ & 99.6 & $\begin{array}{c}\text { Fusarium } \\
\text { equiseti }\end{array}$ & 99.5 & $\begin{array}{c}\text { Fusarium } \\
\text { equiseti }\end{array}$ & 98.6 & $\begin{array}{c}\text { Fusarium } \\
\text { equiseti }\end{array}$ & 98.3 \\
\hline $11 \mathrm{R}$ & $\begin{array}{c}\text { Beauveria } \\
\text { bassiana }\end{array}$ & 98.9 & $\begin{array}{c}\text { Beauveria } \\
\text { bassiana }\end{array}$ & 98.2 & $\begin{array}{c}\text { Beauveria } \\
\text { bassiana }\end{array}$ & 99.0 & $\begin{array}{c}\text { Beauveria } \\
\text { bassiana }\end{array}$ & 98.1 & $\begin{array}{c}\text { Beauveria } \\
\text { bassiana }\end{array}$ & 98.1 & $\begin{array}{c}\text { Beauveria } \\
\text { bassiana }\end{array}$ & 97.6 \\
\hline $13 \mathrm{~L}$ & $\begin{array}{c}\text { Fusarium } \\
\text { equiseti }\end{array}$ & 92.9 & $\begin{array}{c}\text { Fusarium } \\
\text { equiseti }\end{array}$ & 99.1 & $\begin{array}{c}\text { Fusarium } \\
\text { equiseti }\end{array}$ & 99.7 & $\begin{array}{c}\text { Fusarium } \\
\text { equiseti }\end{array}$ & 99.8 & $\begin{array}{c}\text { Fusarium } \\
\text { equiseti }\end{array}$ & 99.0 & $\begin{array}{c}\text { Fusarium } \\
\text { equiseti }\end{array}$ & 98.6 \\
\hline
\end{tabular}

Table 3: Sequencing results and percent identity for ITS, D1/D2, and $\beta$-Tubulin regions for dermatophytic isolates 3R, 4R,11R and 13L.

Four isolates appeared to be tinea pedis- causing species based on their morphology on SBA media, commonly used to culture dermatophytic fungi (22). Isolation of these fungi from $25 \%$ of runners surveyed was consistent with Lacroix et al.'s findings where $27 \%$ of European marathon runners were asymptomatic carriers of Trichophyton spp. (14). Using a more general growth medium (PDA), cultures demonstrated inconsistent morphologies to those of athlete's foot-causing fungi. Isolates $3 \mathrm{R}, 4 \mathrm{R}$, and $13 \mathrm{~L}$ resembled Trichophyton when grown on SBA; however, once placed on PDA, they produced curved, septate macroconidia characteristic of Fusarium species. Isolate $11 \mathrm{R}$ grew as a fluffy white colony on SBA similar to athlete's foot fungi, though microscopic morphology was consistent with Beauveria bassiana on both growth media. SBA media did not hinder spore formation for the species as it did for Fusarium species complex isolates. DNA sequence analysis indicated that none of the isolates were typical species that cause athlete's foot.

It was not surprising that no fungal DNA was amplified using the ITS5/ITS4 primers as it was previously documented that some fungal isolates only work with ITS5/ITS4 or ITS1/ ITS4 (18). All primer set identities agreed except for isolate 3R. This isolate was identified as Fusarium equiseti ( $\beta$-Tubulin and ITS) and Fusarium incarnatum (D1/D2). Inconsistencies about species identification and recognition exist in the Fusarium incarnatum-equiseti complex due to significant genetic variability and need for further research on differences among species $(2,26,30)$. The translation elongation factor 1-alpha and partial RNA polymerase second largest subunit genes have distinguished over 20 species within the Fusarium incarnatum-equiseti species complex; use of both primer sets could identify isolate $3 \mathrm{R}$ to species level $(2,29)$. BLAST scores in the low $90 \%$ range can be explained by limited fungal data in databases and sequencing Phred scores between 20 to 40 (99.0-99.99\% accuracy).

Asymptomatic infections of tinea pedis, referred to as occult tinea pedis, are common among athletes and complicate the spread and diagnosis of tinea pedis (10). While not previously isolated from runners, both $B$. bassiana and members of the Fusarium incarnatum-equiseti species complex are opportunistic human pathogens that can result in superficial dermal lesions to deep tissue, systemic infections $(28,29)$. Long distance runners have depressed immune function and are especially prone to traumatic and environmental dermatoses due to repeated physical stress on their feet and exposure to soil. B. bassiana and Fusarium species are ubiquitous in soil and track and field athletes may come in contact while running through soil during practice and outdoor track meets, which then gets tracked into locker rooms. Limited washing of running sneakers can contribute to repeated exposure to soil fungi directly or through shared surfaces. 
Molecular identification tools, such as sequencing of conserved DNA regions, can improve the consistency and accuracy of identification of dermatophytic fungi (10). This study demonstrated morphological identification could eliminate $75 \%$ of the isolates cultured from runners' feet from being tinea pedis-causing fungi. Four isolates resembled Trichophyton when grown on SBA media, but exhibited atypical morphology when PDA media was used. DNA sequencing was required to determine no isolates were tinea pedis-causing fungi. The presence of opportunistic human pathogens in areas of common tinea pedis infection highlights the need to identify microbes inhabiting asymptomatic and healthy runners. More diagnostic techniques are being developed for dermatophyte identification, such as Matrixassisted laser desorption/ionization- time of flight mass spectrometry, and these tools will continue to improve fungal identification (26). Greater understanding of dermatophytic fungal interactions and their role in disease development can further inform methods of prevention, identification, and treatment.

\section{Acknowledgments}

This work was funded by a Council on Undergraduate Research (CUR) Biology Division research supply grant, St. John Fisher Biology Department research funds, and the St. John Fisher College Center for Student Research \& Creative Work. We would like to thank Dr. Jonelle Mattiacio for critically reading and providing feedback on the manuscript.

\section{Citations}

1. Ahmadi, B., Mirhendi, H., Shidfar, M.R., NouripourSisaakht, S., Jalaziland, N., Geramishoar, M., \& Shokoohi, G.R. 2014. A comparative study on morphological versus molecular identification of dermatophyte isolates. Journal de Mycologie Medicale. 25:29-35.

2. Avila, C.F., Moreira, G.M., Nicolli, C.P., Gomes, L.B., Abreu, L.M., Pfenning L.H., Haidukowski, M., Moretti, A., Logrieco, A., \& Del Ponte, E. M. 2019. Fusarium incarnatum-equiseti species complex associated with Brazilian rice: Phylogeny, morphology and toxigenic potential. International Journal of Food Microbiology 306:1-8.

3. Canavan, T.N., \& Elewski, B.E. 2015. Identifying Signs of Tinea Pedis: A Key to Understanding Clinical Variables. Journal of Drugs in Dermatology 14:42-47.

4. de-Hoog, G.S., Guamo, J., Gene, J., \& Figueras, M.J. 2000. Atlas of Clinical Fungi 2nd Edition. The Netherlands: Central Bureau voor Schimmelcultures Utrecht. 
5. Diongue, K., Brechard, L., Diallo, M.A., Seck, M.C., Ndiaye, M., Badiane, A.D., Ranque, S., \& Ndiaye, D. 2019. A comparative Study versus ITS-Based Molecular Identification of Dermatophytes Isolated in Dakar, Senegal. International Journal of Microbiology 2019:1-6.

6. El-Said, A.H.M. 2001. Mycological and Physiological Studies on Fungi, Isolated from Skin Diseases. Pakistan Journal of Biological Sciences 4:1432-1436.

7. Field, L.A., \& Adams, B.B. 2008. Tinea pedis in athletes. International Journal of Dermatology 47:485-492.

8. Gupta, A.K., \&Versteeg, S.G. 2019. The Role of Shoe and Sock Sanitization in the Management of Superficial Fungal Infections of the Feet. Journal of the American Podiatric Medical Association 109:141-149.

9. Glass, N.L., \& Donaldson, G.C. 1995. Development of Primer Sets Designed for Use with the PCR To Amplify Conserved Genes from Filamentous Ascomycetes. Applied and Environmental Microbiology 61:1323-1330.

10. Ilkit, M., \& Durdu, M. 2015. Tinea pedis: The etiology and global epidemiology of a common fungal infection. Critical Reviews in Microbiology 41:374-388.

11. Jang, J.H., Lee, J.H., Ki, C.S., \& Lee, N.Y. 2012. Identification of Clinical Mold Isolates by Sequence Analysis of the Internal Transcribed Spacer Region, Ribosomal Large-Subunit D1/D2, and $\beta$-Tubulin. Annals of Laboratory Medicine $32: 126-132$.

12. Kovitwanichkanout, T., Chong, A. H. 2020. Superficial fungal infections. Australian Journal of General Practice 48: 706-711.

13. Kurztman, C.P., \& Robnett. C.J. 1997. Identification of Clinically Important Ascomycetous Yeasts Based on Nucleotide Divergence in the 5' End of the Large-Subunit (26S) Ribosomal DNA Gene. Journal of Clinical Microbiology. 35:12161223.

14. Lacroix, C., Baspeyras, M., de La Salmoniere, P., Benderdouche, M., Couprie, B., Accoeberry, I., Weill, F.X., Derouin, F., $\&$ de Chauvint, M.F. 2002. Tinea pedis in European marathon runners. Journal of European Academy of Dermatology and Venereology 16:139-142.

15. Nakasone, K.K., Peterson, S.W., Jong, S. 2004. Preservation and Distribution of Fungal Cultures. In M. Foster, G. Bills(Eds.), Biodiversity of Fungi (pp. 37-47). Academic Press. 
16. Nakasone, K.K., Peterson, S.W., Jong, S. 2004. Preservation and Distribution of Fungal Cultures. In M. Foster, G. Bills (Eds.), Biodiversity of Fungi (pp. 37-47). Academic Press.

17. Nweze, E.I, Mukherjee, P.K., \& Ghannoum, M.A. 2009. Agar-Based Disk Diffusion Assay for Susceptibility Testing of Dermatophytes. Journal of Clinical Microbiology 48:3750-3752.

18. O’Brien, H.E., Miadlikowska, J., Lutzoni, F. 2009. Assessing reproductive isolation in highly diverse communities of the lichen-forming fungal genus Peltigera. Evolution 63: 2076-2086.

19. Okhura, M., Abawi, G.S., Smart, C.D., \& Hodge, K.T. 2009. Diversity and aggressiveness of Rhizoctonia solani and Rhizoctonia-like fungi on vegetables in New York. Plant Disease 93:615-624.

20. Pleacher, M.D., \& Dexter, W.W. 2007. Cutaneoud Fungal and Viral Infections in Athletes. Clinic in Sports Medicine 26:397-411.

21. Pruitt, K., Brown, G., Tatusova, T., \& Maglott, D. 2013. The Reference Sequence ( RefSeq ) Database. In: McEntyre, J., Ostell, J. (Eds.), The NCBI Handbook. (pp. 307-328). National Center for Biotechnology Information.

22. Purim, K.S.M., \& Leite, N. 2014.Sports related dermatoses among road runners in Southern Brazil. Anais Brasileiros de Dermatologia 89: 457-592.

23. Robert, R., \& Pihet, M. 2008. Conventional Methods for Diagnosis of Dermatophytes. Mycopathologia 166:295-306.

24. Sabadin, C.S., Benvegnu, A.A., da Fontoura, M.M.C., Saggin, L.MF., Tomimori, J., \& Tischman, O. 2011. Onychomycosis and Tinea Pedis in Athletes from the State of Rio Grande Do Sul (Brazil): A Cross-Sectional Study. Mycopathologia 171:183-189.

25. Sasagawa, Y. 2019. Internal environment of footwear is a risk factor for tinea pedis. The Journal of Dermatology 46:940946.

26. Sting, R., Eisenberg, T., \& Hrubenja, M. 2019. Rapid and reasonable molecular identification of bacteria and fungi in microbiological diagnostics using rapid real time PCR and Sanger sequencing. Journal of Microbiological Methods 159:148-156.

27. Suh, S-O, Grosso, K. M., Carrison, M. 2018. Multilocus phylogeny of the Trichophyton mentagrophytes species complex and the application of matrix-assisted laser desorption/ionization- time-flight (MALDI-TOF) mass spectrometry for the rapid identification of dermatophytes. Mycologia 110:118-130.

28. Taschdjian, C. 1955. Fountain Pen Ink As an aid in Mycologic Technic. Journal of Investigative Dermatology 24:77-80.

29. Tucker, D.L., Beresford, C.H., Sigler, L., \& Rogers, K. 2004. Disseminated Beauveria bassiana Infection in a Patient with Acute Lymphoblastic Leukemia. Journal of Clinical Microbiology 42:5412-5414.

30. Wang, M.M., Chen, Q., Diao, Y.Z., Duan, W.J., \& Cai, L. 2019. Fusarium incarnatum-equiseti complex from China. Persoonia. 43:70-89

31. White, T.C., Findley, K., et all. 2014. Fungi on the Skin: Dermatophytes and Malassezia. Cold Spring Harbor Perspectives in Medicine.

32. White, T.J., Bruns, T.D., \& Leach, L.D. 1990. PCR Protocols: A Guide to Methods and Applications. In M.A. Innis, D.H. Gefland \& J.J. Sninsky (Eds.), Amplification and direct sequencing of fungal ribosomal RNA genes for phylogenetics (pp. 315-322). Academic Press. 